\title{
Aportes a la filosofía intercultural desde una revisión crítica al concepto de Rakiduam mapuche*
}

\author{
TORBEN ALBERTSEN** \\ Pontificia Universidad Católica de Valparaíso (Chile) \\ torbenalbertsen@hotmail.com \\ LORENA ZUCHEL ${ }^{* * *}$ \\ Universidad Técnica Federico Santa María (Chile) \\ lorena.zuchel@usm.cl
}

\begin{abstract}
Resumen
El propósito de este artículo es introducir al concepto de rakiduam del pueblo mapuche como término relevante para la revisión crítica de una filosofía intercultural. Se propone este término como parte de un diálogo de racionalidades con el que se pretende, como segundo objetivo, vincular el (re) conocimiento de este horizonte-otro (equívoco) con el reconocimiento de nuestros propios horizontes y límites de comprensión, desde dentro de la tradición de la filosofía occidental, y además, en diálogo con la antropología.

Palabras clave: Mapuche, Rakiduam, interculturalidad, hermenéutica, filosofía.

\section{Contributions to an intercultural philosophy from a critical re- view of the Mapuche concept of 'Rakiduam'}

\begin{abstract}
The purpose of this article is to introduce and make a critical revision of the mapuche peoples notion of rakiduam as part of an intercultural philosophy. As part of a dialogue between rationalities we propose to link the recognition of rakiduam as a different (equivocal) horizon to the recognition of our own horizon and limits of understanding from within the western tradition of philosophy, and furthermore, in a dialogue with anthropology.
\end{abstract}

Keywords: Mapuche, Rakiduam, interculturality, hermeneutics, philosophy.

* $\quad$ Este artículo es parte del Proyecto Fondecyt N. 11160332 “Consideraciones filosóficas sobre el reconocimiento. Aportaciones desde los conceptos de 'praxis histórica' e 'interculturalidad' en Ignacio Ellacuría y Raúl Fornet Betancourt”. En parte también está basado en la tesis doctoral titulada: El Otro del Mapuche y El Mapuche como Otro, de Torben Albertsen, realizada en el Doctorado de Estudios Americanos de la Universidad de Santiago de Chile.

** Doctor en Estudios Americanos (Universidad de Santiago de Chile). Actualmente es docente de la Pontificia Universidad Católica de Valparaíso y de la Universidad de Viña del Mar.

*** Doctora en Filosofía (Universidad de Deusto, País Vasco). Actualmente es académica del Departamento de Estudios Humanísticos de la Universidad Técnica Federico Santa María (Chile) e Investigadora responsable del Fondecyt No 11160332 (Conicyt). Ha sido coautora de los libros Contrabandos: Escrituras y Politicas en la frontera entre Bolivia y Chile, La universidad chilena en los albores del siglo XX: Conceptos y experiencias, y Des-Hechos: lo que no se ve de lo tecnológico como desafio.

Recibido: 24/Julio/2018 - Aceptado: 29/Noviembre/2018 
INTRODUCCIÓN

El propósito de este artículo es introducir al concepto de rakiduam, como término relevante para la revisión crítica de una filosofía intercultural.

Si bien es cierto podemos referirnos al rakiduam mapuche inicialmente como "pensar" o "pensamiento" - como generalmente se le conoce-, en este escrito nos referiremos al término desde una propuesta interdisciplinar que congrega una filosofía (y hermenéutica) intercultural (Fornet-Betancourt, 2004, 2007; Salas, 2009, 2011) y una corriente antropológica (Course, 2005; González, 2016; Viveiros de Castro, 2010), que se suele denominar "giro ontológico" (González-Abrisketa \& Carro-Ripalda, 2016). En el centro de esta propuesta encontramos a autores cuyos objetivos disciplinares alojan una compresión sobre inclusión y diversidad de manera crítica, de tal forma que nos ayudarían a acercarnos a ciertos conceptos, como el de rakiduam, del lenguaje mapuche, sin la riesgosa actitud de subsumir o eliminar bajo ideas europeo-occidentales diferencias primordiales; y por otro lado, sin la recurrente insistencia de estudios culturales que proponen ideas y realidades de manera esencialistas o clausuradas.

Lo anterior lo creemos relevante por dos motivos; en primer lugar, por la importancia misma que el término creemos aporta a la reflexión intercultural. Desde aquí, conocer dicho concepto enriquecería una línea de pensamiento que ha venido posibilitando la llamada filosofía latinoamericana y la filosofía africana, los estudios culturales, y variadas disciplinas de las humanidades y ciencias sociales que nos han permitido acceder a un diálogo de racionalidades presentes en las culturas, y que el pensar contemporáneo requiere. Y, en segundo lugar, y por añadidura, nos proponemos realizar este escrito con ánimos de subrayar el necesario reconocimiento de este saber, elaborado por comunidades humanas que históricamente han sido excluidas del diálogo intelectual, y de lo que (in)justamente se ha nombrado "saber". Desde aquí, se espera poder incorporar una reflexión que otorgue elementos a propósitos tan necesarios como la descolonización y la interculturalidad misma.

Para el primer objetivo nos proponemos acceder al concepto rakiduam desde un estudio de sus principales elementos; con tal de contrarrestar un posible significado con las múltiples traducciones del mismo. Pero esto nos llevará rápidamente ya al segundo objetivo; pues creemos que acceder a categorías fundamentales de otra racionalidad nos permitirá darnos cuenta de los límites de la propia comprensión antropológica o de nuestro horizonte filosófico. En un modo hermenéutico intentaremos vincular el 
(re)conocimiento del otro con el reconocimiento de nuestros propios límites en la interpretación. Esperamos entonces que esto nos permita ampliar dicho horizonte para, ojalá, comprender el término aquí propuesto.

Para el segundo objetivo haremos referencia a diversos autores que han ofrecido teorías del reconocimiento desde categorías que creemos relevante insistir. Entre estos, encontramos a Hans-Georg Gadamer y su hermenéutica del lenguaje, autor con el cual iniciaremos este trabajo, pero también a Raúl Fornet-Betancourt, desde unas propuestas de diálogo intercultural con los que esperamos concluir.

Con todo, quisiéramos tener sobre la mesa lo que Viveiros de Castro llama "equivocidad", esto es, un "dispositivo de objetivación" de la antropología (2010: 78), con el que muestra que lo equívoco no es el error o la falta de traducción, sino la diferencia del otro que fundamenta la antropología en su permanente expansión descriptiva. Y, por último, sus transformaciones paradigmáticas, lo que el autor llama la descolonización permanente del pensamiento antropológico (Viveiros de Castro, 2010: 24). Con esta tarea o programación paradigmática se quiere destacar que la filosofía intercultural tiene inquietudes muy similares, empero desde perspectivas fundadas más en la fenomenología o en la hermenéutica. Se puede incluso decir que la filosofía intercultural, por ejemplo, la de Raúl Fornet Betancourt, implica precisamente una descolonización permanente de la filosofía a partir de las diferencias de los otros (la equivocación) o dignificación cognitiva de la diversidad (cultural y/o ontológica).

Vale la pena mencionar también la hermenéutica de Raimundo Panikkar, quien fue una fuente de inspiración temprana de este tipo de pensamiento. En su filosofía, encontramos una forma fundamental de comprender los mitos (o pre-juicios) que guían el logos (la razón). Es a través del encuentro con un mito diferente, esto es, con la equivocidad implicada en la diferencia del otro, que se visibiliza el logos guiado a través del mito. En este sentido, y parecido a la "descolonización permanente" de Viveiros de Castro, una forma de descolonizar en Panikkar se da a través del encuentro con la diferencia del otro.

Desde esta inquietud filosófico-antropológica en común podemos tomar el rakiduam como nuestro "equívoco" o "mito diferente", y entonces pensar que hay algo en él que puede aproximarse a la filosofía. No obstante, para estar seguros debemos primero conocerlo, y en el proceso, reconocer los propios mitos de la filosofía, con tal de ampliar su horizonte y volver la vista al rakiduam. Por mientras, no lo traduciremos como tal, por riesgo de subestimar su diferencia; pero sí lo consideraremos con la intención de dignificar implícitamente su valor equivalente y equívoco posible. 
Para este propósito pensamos que el lenguaje de Gadamer puede ser útil, en la medida en que su hermenéutica también responde a la inquietud que Viveiros de Castro y la filosofía intercultural tiene en común. Se trata, como hemos dicho, de ampliar el horizonte de comprensión de la antropología, como de la filosofía, para acercarnos a una comprensión del rakiduam.

El acercamiento al rakiduam que pretendemos hacer aquí es de todas formas bastante limitado. Un artículo solamente puede captar algo simple en el nexo muy complejo dentro de cual una palabra o "nombre propio" como la del rakiduam se instala. La limitación más fundamental se desprende de una indagación acerca del che (persona), en el mapu-che, y su relación social. No tratamos aquí el rakiduam en su aspecto y relación con el mapu (tierra, cosmos) o su interrelación entre el che y el mapu. Pero no queremos tampoco sugerir con esto la separación o des-asociación (occidental) entre ellos, sino que solamente la capacidad limitada de un tratamiento breve, y su interés por instalar además un diálogo hacia otros horizontes; que esperamos pueda permitir un interés que se aborde en futuros trabajos.

\section{UNAS PRIMERAS APROXIMACIONES A RAKIDUAM, DESDE UNA DIFICUL-} TAD

Rakiduam es una palabra que, como hemos dicho, traducida al español la podemos asociar a pensamiento. Es ese el nombre que dio título, por ejemplo, a un libro de difusión editado por la Universidad de Chile (2014), donde se presentaban los aportes que los quince centros de investigación de dicha casa de estudio han ofrecido a la sociedad, desde diversas áreas disciplinares. El nombre fue entonces elegido para representar el fruto de inteligencias, insertas y activas en la sociedad. Pero ¿por qué escrito en mapudungun y no simplemente en español? Cabe resaltar que en su primera página nos encontramos con una cita de Andrés Bello, fundador de la universidad, que dice: "Lo sabéis, señores, todas las verdades se tocan", y quizá algo ya nos diga de su intención haber elegido precisamente esa cita: un conocimiento universal, una racionalidad que lo abarca todo y lo explica todo, incluso más allá de idiomas, culturas y fronteras; lo que de otro modo se podría llamar incluso filosofía. Al parecer, en todo caso, se trata de dar una identidad al libro, pues, antes de lo de Bello se comenta que rakiduam es una palabra de la tradición oral del pueblo mapuche - "la etnia originaria más numerosa y preponderante de Chile"-; y entonces podríamos decir que se trata de una especie de traducción a una lengua chilena (aunque también se habla en Argentina), que a la vez hablaría de 
Chile. No obstante, ¿será posible simplemente traducir? ¿Será que rakiduam podría representar ese cúmulo de conocimiento de una tradición científica - con toda la carga conceptual e histórica que eso conlleva-, y que en su paso ha seleccionado modos de acercamiento al mundo y la vida?

De eso se trata precisamente este trabajo: acercarnos a una manera de traducción entre pensar y rakiduam, que permita realmente un diálogo intercultural.

\section{GADAMER, LA GRIETA Y LO AJENO}

Proponemos aquí, como perspectiva hermenéutica, y para intentar dialogar con el rakiduam, plantear algunas alternativas desde la filosofía de Hans-Georg Gadamer, y en especial en una serie de lecciones universitarias que elaboró entre los años 1936 y 1959, que son editadas en el libro Verdad y Método del año 1960 (Gadamer, 2007). En esta obra, Gadamer describe el proceso de comprensión en relación a la lectura de textos en un marco de comprensión diacrónico e histórico. Este proceso está guiado por lo que Gadamer llama el horizonte de comprensión del lector, un horizonte que está siempre predeterminado por los prejuicios del lector, que guían la amplitud de dicho horizonte. Gadamer entiende estos prejuicios no en el sentido de la Ilustración como un juicio o subyugación a una autoridad, sino más bien, como lo que guía e informa una comprensión específica, ya sea positiva o negativamente; lo que además permite develar ciertas cosas mientras silencia otras. Desde aquí, agrega un rol positivo a la tradición, de la que no nos podemos sustraer, aún cuando al mismo tiempo nos limita en las posibilidades de lo que podemos comprender:

[...] nos encontramos siempre en tradiciones, y éste, nuestro estar dentro de ellas, no es un comportamiento objetivador que pensara como extraño o ajeno lo que dice la tradición; ésta es siempre más bien algo propio, ejemplar o aborrecible, es un reconocerse en el que para nuestro juicio histórico posterior no se aprecia apenas conocimiento, sino un imperceptible ir transformándose al paso de la misma tradición. (Gadamer, 2005: 27).

Gadamer, además, propone que nunca leemos un texto para entenderlo para nosotros mismos - "para sí mismo"- o para comprender de modo autónomo la propia auto-comprensión del autor en su contexto diacrónico. Aunque este puede guiarnos como pauta en nuestra lectura, no es posible separar por completo nuestro propio horizonte de comprensión del horizonte que informó al texto y su escrito. No es posible entender el texto en el sentido como otro, o en el sentido original del autor, no obstante 
pueda acercarse a ese horizonte original. Este proceso de comprensión lo describe como una fusión de horizontes. Se refiere a la fusión del horizonte del lector con el horizonte (diacrónico) que el texto presenta. Esto significa que la comprensión nueva (del lector), o su fusión de horizontes, es siempre diferente del horizonte del texto; y en la medida que el texto nos inspira, también hace diferente nuestro horizonte original; es decir, se aprende algo nuevo y el resultado es una ampliación del horizonte propio del lector en la medida que logra integrar (o fusionar) algo del horizonte que abre el texto.

Es importante aclarar aquí que el sentido del texto o el horizonte del texto no se puede agotar, no solo porque no se pueda fijar, sino también porque cada lectura es diferente. Para Gadamer, el asunto clave de la hermenéutica que juega un rol importante en esta fusión de horizontes es la tensión "entre medio" de los dos horizontes de comprensión. Esta tensión se establece porque el lector comprende algo del texto, tiene algo en común con su horizonte propio, pero a la vez hay cosas que no logra entender, es decir, a la vez el horizonte del lector diverge y converge con el horizonte del texto.

Aplicando el lenguaje hermenéutico de Gadamer para explicitar la comprensión del rakiduam, podríamos decir que no estamos ante la presencia de un "texto", de un "lector" y de un "escritor", al menos no en sus sentidos literales. Además, la distancia hermenéutica (entre medio de los horizontes) no es solamente diacrónica sino además diatópica, una dimensión que Gadamer no desarrolló mucho (Calandín, 2017). Es un "nombre propio" que figura activamente en la mente de un pueblo específico y contemporáneo. A pesar de estas diferencias, y la falta de la dimensión sincrónica de Gadamer, nos parece aplicable el lenguaje hermenéutico de Gadamer debido a dos cosas. Primero porque presupone que lo que entendemos, nuestra fusión de horizontes, siempre es diferente de los horizontes propios de los mapuches que comprenden al rakiduam. Y segundo, porque el lenguaje pone énfasis en los prejuicios, es decir, en el reconocimiento de los límites y lo estrecho del horizonte de la filosofía en hacer el intento de interpretar (o describir) al rakiduam.

Esta manera de indagar tiene su centro paradigmático en la descolonización permanente y la importancia en conocer el mito del otro para el autoconocimiento (o la descolonización) del mito propio, o alternativamente, la fusión (aprendizaje) del horizonte propio. No obstante, queremos sugerir una manera que profundiza de modo más específico la noción de "tensión" reflexionada por Gadamer, y entonces queremos sugerir el reemplazo de esta palabra por la noción de grieta. Lo que oponemos aquí es una connotación específica asociada a la palabra tensión, utilizada a me- 
nudo por las ciencias naturales. La dificultad que encontramos en la palabra tensión la hallamos en la connotación que implica una suerte de equilibrio o balanza entre y a partir de fuerzas opuestas, como en el caso de los magnetos. Y entonces, si se pretende usar la palabra para describir la relación entre rakiduam y filosofía nos enfrentamos a una serie de problemas.

Primero. Hallamos una diferencia que no se encuentra en los magnetos, y nos referimos a la carga histórica que ha propiciado diferentes relaciones reales de poder. No hay aquí ningún equilibrio o balanza entre contrarios, pues no poseen ambos conceptos la misma "fuerza" de poder. La institucionalidad de la filosofía, el reconocimiento que ha obtenido en Chile desde la creación de las primeras universidades, ya da muestra de una relación asimétrica que impediría al rakiduam exigir a la filosofía. Al contrario, el poder de la filosofía que ya esta institucionalizada, le permite, si estima necesario y valorable, abrirse o no a un diálogo con nociones ajenas como la del rakiduam (algo quizá como lo que podríamos estar haciendo con este trabajo).

Segundo. No estamos en presencia, a pesar de todo, de relaciones opuestas. Opuestas, al parecer, como la luz y la oscuridad, como el progreso y el atraso. Este asunto nos parece de importancia fundamental en la medida que la diversidad o pluralidad no se contiene dentro de ningún modelo dualista, sino que es precisamente este dualismo el que lleva frecuentemente a estereotipar al otro y finalmente lo conduce hacia un telos mono-cultural. La comprensión de la diferencia, y en extensión, la pluralidad real, no va a poner como opuesto el uno frente al otro, no obstante que necesite poder comprender los conflictos y los modos que el uno podría oponer al otro.

Y entonces, creemos que la connotación de la tensión opera en un aparente "entre medio", pero sin divulgar o indagar acerca del sujeto y la dirección fenomenológica. ¿Quién o qué se tensiona con qué? Y ¿desde qué "lado" está situada la perspectiva? En Gadamer, y en la medida que la tensión existe en la fusión del horizonte, esta respuesta es obvia, pero al aplicar su hermenéutica a un contexto más grande, y en la medida que la parte del conflicto tiene que ponerse en el centro del debate, se necesita una noción que tome este asunto de modo más preciso.

$\mathrm{El}$ "cuerpo" de tensión situado "entre medio" es una noción demasiado abstracta, no existe ningún "cuerpo" entre medio del rakiduam y la filosofía, sino que solamente existen comprensiones desde el uno o desde la otra. No hay ningún comparans entre medio de dos comparanda (filosofía y rakiduam) sino que solamente sujetos que se involucran en el uno o en el otro, o alternativamente en ambos, pero nunca en una medida "igual", o matemáticamente igual. 
Estamos ahora mismo situados desde la filosofía preguntando hacia el rakiduam. El problema por lo tanto es con la connotación (de la tensión) como algo puesto "entre medio" de modo neutro o neutral. A partir de estos problemas queremos ofrecer otra noción, la palabra grieta (Albertsen, 2017), que versa sobre rupturas y, por ende, visibilización del conflicto recién presentado.

La grieta, o en su verbo, agrietar, es una potencial ruptura de algo solido, algo que ya está establecido. Lo solido sería la tradición, con sus prejuicios (en sentido positivo tanto como negativo), es decir, en ideas de Gadamer, lo que guía al horizonte del sujeto que intenta comprender. Por lo tanto, la grieta ofrece una dirección intencional (fenomenológica) a la tarea hermenéutica en la medida que pregunta por la tensión de un modo mucho más específico-crítico, ¿qué agrieta a la filosofía (o al filósofo) el encontrarse con el rakiduam, ya sea en formas conceptuales, sociales, existenciales, contextuales etc.?

Este proceso, y en la medida en que siempre pregunta fenomenológicamente a la fuente de la tensión de sentido y de conflicto, evita abstraer el contexto social y vivencial, y permite dirigir la atención hacia el proceso de fusión del uno o del otro para evitar que la perspectiva pretenda neutralidad. Si se pregunta por lo que agrieta, este requiere al sujeto que haga una interpretación comprometida con una u otra perspectiva y horizonte, es decir, situarse en el contexto del encuentro. Y entonces, se agrieta, es decir, se opone (o pone desde un lado de la grieta) desde una perspectiva especifica, y así se puede más fácilmente evitar también la abstracción de la oposición dual. Al mismo tiempo permite precisamente centrar la pregunta hacia los prejuicios, en la medida que lo que agrieta se relaciona directamente con algo que opone, o a la falta de comprensión del horizonte. Además, acerca directamente hacia lo equivoco del otro, y esto ocurre porque la "equivocación del otro" corresponde fenomenológicamente a los prejuicios. Se podría decir, lo equivoco agrieta lo sólido, y eso se fundamenta en los prejuicios. Es el paso siguiente, y fenomenológicamente necesario, desde la detección de una equivocación hasta llegar a una descolonización potencial.

\section{RAKIDUAM}

Para interpretar y traducir el horizonte del rakiduam mapuche es importante al inicio indicar una salvedad, más allá de limitarnos al che (sin el mapu). Pretendemos aquí solamente tocar una dimensión del rakiduam, una dimensión que en análogo podríamos describir como una rama de un árbol mucho más grande y compleja en esta breve reflexión. Otra dimensión podría ser su relación con el nütram (como diálogo o conversación), en 
torno a la pregunta por el intercambio fructífero de perspectivas en relación a la recuperación y la transferencia de la tradición. Pero de modo general, consideramos que el rakiduam existe en una relación íntima con la lengua (mapudungun), las experiencias y las acciones; y estos tres aspectos, a la vez considerados como momentos personales tanto como sociales. Volvemos a este asunto después de hacer una traducción inicial y simple (con diccionario) del rakiduam.

Las traducciones más comunes de rakiduam en los diccionarios son "mente", "mentalidad”, "pensar", "pensamiento", “intención”, “opinión” e "inteligencia". Pero el rakiduam es una palabra compuesta por dos palabras, el rakin y el duam. La raíz de rakin se traduce comúnmente por "contar" o "calcular". Si vemos esta entrada desde el castellano en Augusta (1916), se entiende básicamente dos nociones, primero la de hacer cálculos en el sentido asociado con la numeración y la matemática; y la segunda, en el sentido social de poder contar con alguien, sea por ejemplo en términos de fidelidad o en términos de contar con sus habilidades para algún propósito. Por lo tanto, podríamos notar ya en rakin dos definiciones. Primero, la de "calcular", que es el "contar" o el razonamiento de los números (RA1); y segundo, el "contar con alguien" (RA3), el razonamiento en un sentido social.

Por su parte, el duam tiene un significado mucho más diverso y difícil de apuntar. En Augusta se traduce principalmente como "intención", "necesidad" y "urgencia". En Musigraf (2003) se traduce como "voluntad", "deseo", "intención" y también "necesidad". Y en Navarro (2002) se traduce como "afectos", "idea", "necesidad", "intención" y "urgencia". Desde el castellano también se traduce frecuentemente "sentimiento" con duam. Así mismo pasa con los diccionarios de Navarro y también Augusta que realizan esta misma traducción; aunque, además, directamente con rakiduam y también con pinke, que, de vuelta, se traduce con "corazón" y "sentimiento del corazón”. Si vamos más atrás, a Febres (1765), su sentido parece ser aún más disperso, incluyendo, por ejemplo, "memoria", "entendimiento", "gusto", "condición", "ganas", "pensamiento", entre otros. En Febres también existe una definición que se refiere a una persona que "no tiene dos caras" o dos intenciones o "que no es doblado", es decir, correspondiente a quien no juega chueco al otro.

Para tomar en consideración una interpretación y traducción más compleja (más allá del diccionario), hay que explicitar que el rakiduam no es exclusivo a algunos mapuches, sino que todos los mapuches tienen rakiduam - tal como todos los chilenos tienen pensamiento-. No obstante, podríamos encontrar distinciones en la aplicación del "buen" (küme) rakiduam, lo que no incluye, en todo caso, una cierta jerarquización (y valoración) antropológica, como en la tradición del pensamiento occidental con 
la filosofía, por ejemplo: Desde allí, no cualquier persona podía llegar a ser filósofo o poseer un rakiduam muy valorado.

El antropólogo Marcelo González (2016) propone lo que define como una teoría mapuche de la verdad, y con esto se refiere a aspectos centrales que determinan la veracidad. Explica que la verdad es dependiente de la experiencia personal, lo que llama una fenomenología personal, y que la única manera de conseguir saber real es experienciándolo personalmente (2016: 56). Propone que la experiencia no se distingue analíticamente del rakiduam sino que esa distinción se logra al utilizar la explicitación de los mismos en el lenguaje (mapudungun). Es decir, mientras que el rakiduam y la experiencia personal son prácticamente lo mismo, se distingue entre "ellos" por el lenguaje que se emplea para describir las experiencias del rakiduam. Para González este es el lugar donde se instala la duda y la incerteza. Esta duda se explicita con dos preguntas; primero, ¿cuán congruente es la relación entre el pensamiento de una persona y el lenguaje? Y en un sentido social, ¿cuán cercano es este pensamiento personal (de un "otro-mapuche") al pensamiento propio? (González, 2016: 63). Dicho de otra manera, por un lado, ¿qué tan congruente es mi relación propia entre lenguaje y experiencia/rakiduam? Y por otro lado, ¿qué tan congruente es esta misma relación en los otros?1

Esta teoría de la verdad está en la línea de lo que Magnus Course propone como la irreductibilidad del che o de la persona mapuche; es decir, lo que señala a cada persona como algo fundamentalmente irreductible y único (Course, 2005). La irreductibilidad de la persona mapuche en Course tiene una congruencia teórica con la irreductibilidad de cada experiencia/rakiduam en González, pues, si las experiencias son únicas, el che es único, y viceversa. Es importante notar aquí que "la persona", en esta interpretación antropológica se diferencia de "lo humano" en el sentido tradicionalmente moderno en cuanto "lo humano" presupone una unidad a partir de la naturaleza (por ejemplo, genética) mientras que el che no presupone tal unidad.

En este sentido, y siguiendo a González, aquí la verdad es un asunto personal en la medida en que es fundada en experiencias personales y particulares (rakiduam), que emergen de cada involucramiento personal con el ambiente. Cada rakiduam es una experiencia de alguien y una experiencia directa con el mundo, y no es susceptible de ser cuestionada por otros. Lo

1 Al margen de lo señalado, González abre camino a una contradicción aparente y vivencial, porque explica que los mapuches quisieran contar sus experiencias, y que otros hagan lo mismo con ellos. González propone que esto se podría deber a que las experiencias de otros podrían substituir la ausencia de la experiencia personal sobre un asunto (2016: 63-64). 
que siempre es verdadero y auténtico (y por extensión, irreducible) es la experiencia personal.

González propone que los mapuches no cuestionan la experiencia propia del otro, sino su forma de interpretación, es decir, la experiencia/rakiduam expresada como lengua. Lo que se pone en duda del otro es la conexión o relación entre, por un lado, la experiencia/rakiduam (denotatum), y por otro lado el lenguaje (denotación) (González, 2016: 64), lo que llama "la opacidad de la mente de los otros" (2016: 64-65). Explica que las palabras mupin (decir la verdad) y koyla (mentir) pueden ser aplicadas para denominar esta conexión, lo que se cree que significa el lenguaje usado del otro para explicitar su experiencia/rakiduam.

Estas interpretaciones antropológicas pueden complementar algo que se puede entender con el término "integridad" (Albertsen, 2017). Con integridad nos referimos aquí a un valor de unidad integral o coherencia personal y social que nos parece que los mapuches ponen como central, y que frecuentemente se asocia con la palabra rakiduam y con la palabra nor (recto). Proponemos la palabra "integridad" como otra forma de explicitar un valor implícito en el rakiduam, tomando en consideración con ella la irreductibilidad del che (de Course) y la congruencia en términos de veracidad (de González). Sí cada rakiduam/experiencia es irreducible de por sí, supone que es integrable en relación a un todo, el che, cuya perspectiva figura de modo total en relación a ellos, y que suma en un che irreducible. Supongamos también que la lengua, dentro del mismo che, debe imaginarse como integrado (coherente/congruente) con sus propias experiencias/rakiduam, y entonces podemos describir este imaginario con la palabra transparencia. El che, que se imagina un ser integral, debe contemplar una transparencia entre sus experiencias/rakiduam y su uso del lenguaje. En cierto sentido, la transparencia aquí la usamos para describir el contrapunto imaginario/ideal de la duda y la opacidad de la mente de los otros, de González.

Por lo tanto, la relación entre la experiencia/rakiduam y el lenguaje debe ser lo más transparente posible, es decir, en contraste con la opacidad de la mente de los otros. El rakiduam bueno (küme), en un plano personal, debe entonces buscar una transparencia personal en relación al lenguaje. Esto se conseguiría más fácilmente siendo integral, logrando una integridad personal real. Las palabras mupin (verdad) o koyla (no verdad) pueden ser aplicadas para designar si es que se considera lo que el otro dice (su lenguaje) como transparente con sus experiencias.

Estas acepciones son posible encontrarlas expresadas metafóricamente en algunos diccionarios. Por ejemplo, los sentidos de un ser "doblado", "chueco", o que "tiene dos caras" son utilizados frecuentemente, 
implicándolos además con el "contar con" el otro. La transparencia personal se extiende así hacia una dimensión social, una transparencia social en la medida en que el otro puede interactuar, estar de acuerdo o dudar de mi forma de poner lengua a mi transparencia personal. De este modo la transparencia personal es en cierto sentido recíproca con la construcción de una transparencia social.

$\mathrm{Al}$ aplicar la palabra rakiduam a una traducción equivalente (pero equívoca) como pensar, mentalidad, pensamiento, concepto, inteligencia, sin más, se deja de lado el uso complejo de un imaginario que valora ante todo la unidad/dificultad que se vive en la integridad personal y social. Es frecuente advertir frases como "tenemos que pensar todos lo mismo", "rakiduam no es solamente pensar, sino que pensar unido", "se trata de pensar un solo pensamiento" (Albertsen, 2017). Bajo estas perspectivas, estas formulaciones parecen expresar un imaginario de una unidad social cuya transparencia social corresponde o es coherente con las múltiples transparencias personales. Pero, en la medida que las mentes de los otros son opacas y su che irreducible, tanto más parece importante la necesidad de construir una sociabilidad en común, una transparencia compartida. Ambos, González y Course, discuten este asunto. Los che no son ya unidos de antemano (por naturaleza, como refiere una tradición occidental) sino cada uno tiene que construir esta sociabilidad durante su vida. Course concluye diciendo que la sociabilidad no es el "resultado de una necesidad" sino más bien una "necesidad en sî" (2005: 275).

Queremos agregar a esta discusión otra palabra que nos parece muy relevante y que permite una interrelación del asunto con una dimensión más deontológica y normativa. Esta palabra es la palabra nor, o su personificación como norche. Hay principalmente tres palabras que traducen la palabra nor de modo simple, "derecho", "recto" y "sincero". En Musigraf y Augusta se traduce como "derecho" o "ser derecho", y también con "arreglarse (un asunto)"; mientras que en Navarro la palabra se entiende como "derecho", "derechamente" y "recto". En Febres, también se traduce nor como "derecho".

Augusta apunta a que nor no solamente indica a algo correcto en el sentido moral o normativo, sino que también a algo "recto" en el sentido espacial de una "línea recta" o un "camino derecho". No obstante, al describir rakiduam en este sentido espacial siempre se ocupa en un sentido metafórico con connotación frecuentemente normativa, o de una conducta recta o correcta. Por lo tanto, aquí nor es lo recto principalmente en referencia a las relaciones sociales y en su sentido metafórico. Un hombre recto por ejemplo puede hablar con nor dengun que significa "hablar con sinceridad sin ambages ni efugios" (Augusta) o sin mentir (koyla) o doblar 
su forma recta. Aquí de nuevo poniendo énfasis en la transparencia personal/social. Muchos mapuches refieren a un norche como una persona incluso bien difícil y porfiada, ya que sigue su camino pase lo que pase (Albertsen, 2017). El nor también está implicado en el rakiduam directamente a través de las traducciones que se hacen del duam. Desde el castellano (en Augusta) se traducen palabras como "decisión", "decidirse", "resuelto", "resolver" y "resolución" con la palabra de duam; mientras que la palabra "aclarar" se traduce con el nor. En el duam, por lo tanto, existen implícitamente las cualidades que se asocian con el nor, un ser resuelto. Un rakiduam bueno (küme) por lo tanto aspira a un pensar/pensamiento recto y resuelto, que incide con la transparencia personal y social. El nor refleja un imaginario acerca de un tipo de persona que es confiable y honesta, además de ser resuelta y aclarada; esto es, que tiene transparencia personal acerca de sí mismo, y transparencia social en relación con otros.

\section{AlgunAS POSIBLES GRIETAS DESDE EL RAKIDUAM}

La posibilidad de la transparencia social, y la condición bajo el cual el rakiduam construye su horizonte, se fundamentan en relaciones que son directas y personales, es decir, en el cara-a-cara, donde se puede de mejor manera hallar lo que hemos explicado como la transparencia del otro (que tiene sus propias experiencias, irreducibles a las mías). El horizonte del rakiduam agrieta fundamentalmente el tipo de institucionalidad moderna que se condiciona a partir de la lejanía y distancia entre gentes. Esta institucionalidad, por definición, se aleja de una buena (küme) sociabilidad. La construcción de una sociabilidad a partir de la distancia entre gentes es en principio una idea que se agrieta desde el horizonte del rakiduam. Los papeles, las firmas y los certificados no pueden substituir la transparencia que posibilita la relación directa. Es menester considerar además la condición del kimün, como un conocimiento oral, o que se intercambia de modo oral y directo a través del dialogo (nütram).

Estos requerimientos se pueden observar también en los ritos mapuches. En el juego del palin, por ejemplo, uno de los pilares centrales es la relación directa y personal entre los "pares opuestos" de jugadores, los que están en lugares contrarios y en recta competencia durante el juego. La relación entre ellos es central para el juego, y se denomina a la vez kon-wen (amigo-mutuo) y kayne-wen (enemigo-mutuo) (Course, 2005: 208-239). Es interesante notar aquí que no existen árbitros en este deporte. Se decide todo entre los capitanes de cada equipo sin ninguna tercera figura que opere regulando la situación con reglas desde una supuesta posición neutral y superior o transcendente en relación a los lados involucrados. Por otro lado, en el eluwün o funeral mapuche, el discurso funerario o amulpüllün 
se centra no sólo en el diálogo directo entre dos oradores (wewpife), sino que además el propósito de esta interlocución es narrar o contar, y con esto, hacer transparente toda la biografía y los logros en la vida del difunto, de manera que se hace completo (a través de su narración) el püllü (espíritu) para que se pueda ir (amul) con tranquilidad (Course, 2005: 170-194).

Sí cada uno es dueño de su propio rakiduam, hay además un aspecto que impulsa una organización e institucionalización desde abajo, o que se construye en una sociabilidad a partir del primer contacto entre las personas mismas, y no desde arriba, o desde una institucionalidad ya instalada y presionando hacia abajo.

La transparencia personal y social en el horizonte del rakiduam además parece buscar lo inmanente del ser. Pues, en primer lugar, la verdad no transciende a las personas mismas, debido a que su extensión social se fundamenta en la transparencia personal de cada che. Con esto, el horizonte del rakiduam no está dedicado a la búsqueda de una verdad universal, si es que se entiende esta como lo que transciende a lo personal e individual, o su extensión social. Esta agrieta por ejemplo la forma de pensar la naturaleza humana como algo universal en la medida en que se lo piensa como la unidad humana a partir de la cual se construye una diversidad cultural. Aquí una unidad podría ser la irreductibilidad del che (Course, 2005), a partir de la cual se puede construir una diversidad social compleja.

\section{RAKIDUAM Y SUS DESAFÍOS PARA LA INTERCULTURALIDAD. A MODO DE CONCLUSIÓN}

La comprensión de Rakiduam es tan compleja como las pocas páginas aquí escritas pudieran expresar. Se ha intentado hasta ahora una aproximación a ciertos conceptos que explicarían esta dificultad, pero aún tantos otros constitutivos de la "grieta" quedan sin abordar. Quedan "espacios, momentos y fenómenos" necesarios para comprender no tan sólo el concepto que aquí nos convoca, sino también para entender su valor en aspectos socio políticos, como la noción de wiñon antü o we xipantu, que vino a reivindicar la cultural mapuche en el año $1979^{2}$ (Catriquir \& Llanquinao, 2017: 119). Otro aspecto es el del tiempo, término que involucra a la vez acciones como los ritos, sentimientos como la alegría y creencias como las personificaciones, no sólo en personas, sino también en edades y territorios (Catriquir \& Llanquinao, 2017: 135); todas estas son cuestiones que no encontramos en alguno de los conceptos que posee nuestra lengua, y

2 En 1979 se produce un movimiento de resistencia detrás del Decreto Ley 2568 impulsado por la dictadura de Pinochet, que buscaba dividir las tierras mapuche y transformarlas en propiedades individuales. 
que difícilmente podríamos relacionar. Es justamente esta última dificultad la que quisiéramos mencionar, ya no como aporte para la comprensión del rakiduam, sino, desde allí, como contribución para la interculturalidad.

La interculturalidad la entendemos como un proyecto de liberación, en el sentido de que no se trata de cualquier relación entre culturas, sino de un proyecto complejo que apuesta por la transformación de la realidad, desde una posición de reconocimiento de todas las culturas como realidades históricas. En palabras de Raúl Fornet-Betancourt, diríamos que la interculturalidad no es:

[...] una posición teórica ni tampoco un diálogo de y/o entre culturas (o, en este caso concreto, un diálogo entre tradiciones filosóficas distintas) en el que las culturas se toman como entidades espiritualizadas y cerradas; sino que interculturalidad quiere designar más bien aquella postura o disposición por la que el ser humano se capacita para... y se habitúa a vivir "sus" referencias identitarias en relación con los llamados 'otros', es decir, compartiéndolas en convivencia con ellos. (2004: 14-15)

En efecto, la intercultural es una experiencia, es una vivencia "de la impropiedad de los nombres propios" (Fornet-Betancourt, 2004: 15) y por lo tanto también es un desafío a estar continuamente abriéndose a otras realidades que le remueven y le transforman. Desde ahí, se puede agregar que la interculturalidad es una disposición además dolorosa, en la formulación de un descentramiento de las historias propias.

Con el Rakiduam, como hemos visto, ocurren miradas que favorecerían estas experiencias; pues, se trata de un modo de comprensión que nos descentra, pero también se trata de un concepto abierto, que se vivencia en lo que podríamos llamar praxis histórica; en el sentido de un motor que va posibilitando la evolución de la realidad histórica; esto es: incluyendo lo que ha hecho que tal realidad sea lo que es, pero saliendo de sí hacia direcciones que no son posibles de predecir (Ellacuría, 1990). Esto lo podemos ver en el concepto mismo que aquí analizamos, pero que ya sabemos es más que un concepto, es un cúmulo de acciones, experiencias, creencias, que incluyen un permanente "fuera de foco" para sí mismo, y que favorecen la sociabilidad. Pues, como dijimos, nada más importante en el rakiduam hay que la transparencia; ese sacar a la luz, hacia fuera, todo lo que mueve nuestras acciones, para enseñar la integridad que se persigue. Se trata, entonces, de un hacia fuera lo que hay dentro, en el espíritu, y de modo verdadero. Ya sea de modo biográfico o social.

No se trata entonces de modos cerrados de vida, de costumbres ni pensamientos. Ni siquiera en los ritos, que repiten sin cesar acciones de 
antaño; porque incluso allí, donde veríamos con más exactitud una insistencia en el pasado, un cierto anclamiento, se trata de un momento necesario de vivencia, de una comprensión compleja del tiempo que revive momentos del pasado, en el presente; de modo de seguir hacia delante ya purificados; con una vida nueva que avanza en un tiempo y espacio, y al vaivén del sol, de la luna y de la naturaleza (Torres \& Quilaqueo, 2011).

Esto pasa también con los significados ofrecidos para comprender la palabra grieta, de la que nos hemos referido. Pues, grieta, hace referencia a la palabra "discurrir" — que se usa ampliamente en las tradiciones del pensamiento occidental_. La etimología de la palabra "discurrir" en latín tiene dos componentes, el prefijo "dis", que significa separación múltiple, y "currere", que significa correr. Por lo tanto, no es un correr cualquiera o rápido, sino que un correr que se separa o que se mueve hacia múltiples lados o en múltiples direcciones, un correr siempre "hacia fuera", o transcendiendo a sí mismo. En el diccionario de la RAE esta palabra tiene una íntima red de significaciones y relaciones de sentidos entre palabras como discurso y razón: la razón misma siendo la "facultad de discurrir" (RAE1). Al contrario, la palabra "incurrir", que significa correr "hacia dentro" (in), significa en el diccionario "caer en una falta, cometerla" (RAE1) o "causar o atraerse un sentimiento desfavorable" (RAE2). Es decir, en la convención oficial del castellano, la razón que reflexiona "hacia dentro", o de modo inmanente, ya está cometiendo un error. Dicho de otra manera, el modo de pensar de una razón transcendente ya está encarnado "como correctivo" en la lengua del castellano. Desde aquí, el modo inmanente del horizonte del rakiduam agrieta este horizonte transcendente y razón occidental. Y es que precisamente esto es lo que se ha intentado con este trabajo: poner en problemas a nuestra racionalidad, agrietarla y salir de ella para pensarla y atrevernos a desafiarla continuamente desde la relación con las otras; desde el reconocimiento continuo de que yo, mi centro, mi acomodamiento, no es sino una de tantas maneras de vivir y sentir la vida y el mundo.

\section{REFERENCIAS}

Albertsen, T. (2017). El Otro del Mapuche y El Mapuche como Otro. Tesis Doctoral. Santiago: IDEA. USACH.

Augusta, F. J. (1916). Diccionario Araucano-Español; Diccionario Español-Araucano. Disponible en: http:/ / fiestoforo.cl/dungun/aug/

Calandín, J. (2017). Autosuperación hermenéutica de la cultura en la interculturalidad. Hacia una lectura intercultural de la hermenéutica filosófica de Hans-Georg Gadamer. Ideas y V alores, 66(164), 265-280. 
Catriquir, D. \& Llanquinao, G. (2017). Wiñon antü zugu. Fenómeno natural, de vida y de kimün en el mapunche rakizuam. En R. Becerra \& G. Llanquinao (eds.), Mapun kimün. Relaciones mapunche entre persona, tiempo y espacio (pp. 119136). Santiago de Chile: Ocho Libros editores.

Course, M. (2005). Mapuche Person, Mapuche People, Individual and Society in Indigenous Southern Chile. London: London School of Economics and Political Science.

Ellacuría, I. (1990). Filosofía de la realidad histórica. San Salvador: UCA Editores.

Febres, A. (1765). Arte de la lengua general del Reyno de Chile. Lima.

Fornet-Betancourt, R. (2004). Crítica intercultural de la Filosofía Latinoamericana actual. Madrid: Trotta.

Fornet-Betancourt, R. (2007). La filosofía intercultural desde una perspectiva latinoamericana. Solar, (3), 23-40.

Gadamer, H. G. (2005). Verdad y método I. Salamanca: Sígueme.

Gadamer, H. G. (2007). Sandhed og Metode. Grundtrak af en Filosofisk Hermeneutik. (A. Jørgensen, Trad.) Aarhus: Académica.

González, M. (2016). Los mapuche y sus otros. Persona, alteridad y sociedad en el sur de Chile. Santiago: Universitaria.

González-Abrisketa, O. \& Carro-Ripalda. S. (2016). La apertura ontológica de la antropología contemporánea. Revista de dialectología y tradiciones Populares, LXXI(1), 101-128.

Musigraf (sin nombre) (2003). Diccionario mapuche mapudungun, español-mapudungun/ mapudungun-español fonética, sistema numeral, toponimia. Chile: Musigraf.

Navarro, D. (2002). Breve Diccionario español-mapuche, mapuche-español. Santiago: MINEDUC, Ser Indígena.

Panikkar, R. (1979). Myth, Faith and Hermeneutics. New York: Paulist Press.

Salas, R. (2009). De la liberación soñada a la globalización imaginada: Crítica intercultural de la simbólica latinoamericana. En J. Santos (ed.), Integración e Interculturalidad. Desafíos pendientes para América Latina (pp. 93-108). Santiago: Universidad Santiago de Chile.

Salas, R. (2011). Filosofía Occidental y Filosofía Mapuche: Iniciando un Diálogo. Revista ISEES, (9), 119-138.

Torres, H. \& Quilaqueo, D. (2011). Conceptos de tiempo y espacio entre los mapuches: racionalidad educativa. Papeles de trabajo - Centro de Estudios Interdisciplinarios en Etnolingüistica y Antropología Socio-Cultural, (22), 13-27.

Universidad de Chile (2014). "Rakiduam". Disponible en http://web.uchile.cl/archivos/vid/archivos/Rakiduam/files/assets/common/downloads/RAKIDUAM $\% 20-\% 20 \mathrm{El} \% 20$ pensamiento.pdf

Viveiros de Castro, E. (2010). Metafísicas caníbales, líneas de antropología postestructural. (S. Mastrangelo, Trad.). Madrid: Katz Editores.

Sumario: Introducción; 1. Unas primeras aproximaciones a rakiduam, desde una dificultad; 2. Gadamer, la grieta y lo ajeno; 3. Rakiduam; 4. Algunas posibles grietas desde el rakiduam; 5. Rakiduam y sus desafíos para la interculturalidad. A modo de conclusión; Referencias. 